\title{
Flexibilización del modelo de insumo-producto para determinar interdependencias productivas en la ciudad fronteriza de Reynosa, Tamaulipas, 2013
}

\section{Flexibilization of the input-output model to determine productive interdependencies in the border city of Reynosa, Tamaulipas, 2013}

Recibido el 7 de diciembre de 2018. Aceptado el 27 de junio de 2019. Publicado el 14 de agosto de 2019.

*Autor para recepción de correspondencia: Rodrigo Vera Vázquez, correo electrónico: ecovera2007@gmail.com

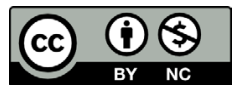

Esta obra está protegida bajo una Licencia Creative Commons Atribución-NoComercial 4.0 Internacional.
Rodrigo Vera Vázquez a* (1) https://orcid.org/0000-0001-9200-4428 Miguel Angel Langle Flores ${ }^{\mathrm{a}}$ (D) https://orcid.org/0000-0002-6260-5537

\begin{abstract}
${ }^{a}$ El Colegio de Tamaulipas, Ciudad Victoria, Tamaulipas, México, correos electrónicos: ecovera2007@gmail.com, angel120425@hotmail.com
\end{abstract}

\section{Resumen}

Con información económica del año 2013, se sugieren estrategias de política económica regional para el municipio fronterizo de Reynosa, Tamaulipas. A partir de los modelos de Leontief y Flegg, Webber y Elliot, se construye una matriz de insumo-producto regional y su correspondiente análisis de multiplicadores. Para complementar el procedimiento, se tipifica la influencia de la actividad industrial y se brinda una visión estructural de los encadenamientos productivos siguiendo a Rasmussen. Los resultados muestran el carácter marginal de los multiplicadores de producción, empleo, remuneración de los asalariados y valor agregado en las actividades productivas no manufactureras.

Palabras clave: Reynosa, Tamaulipas, insumo-producto, manufactura, economía.

\section{Abstract}

Strategies of regional economic policy are suggested for the border municipality of Reynosa, Tamaulipas, resulting from the analysis of economic data of 2013. A regional input-output matrix and its corresponding multiplier analysis are constructed taking as starting point Leontief and Flegg, Webber and Elliot models. Besides, the influence of the industrial activity is classified and a structural vision of the productive chains is provided, following Rasmussen. The results show the marginal nature of the multipliers of production, employment, income and value added in non-manufacturing productive activities.

Keywords: Reynosa, Tamaulipas, input-output, manufacturing, economy.

CÓMO CITAR: Vera, R. y Langle, M. A. (2019). Flexibilización del modelo de insumo-producto para determinar interdependencias productivas en la ciudad fronteriza de Reynosa, Tamaulipas, 2013 [Flexibilization of the input-output model to determine productive interdependencies in the border city of Reynosa, Tamaulipas, 2013]. Estudios Fronterizos, 20, e030. doi: https://doi.org/10.21670/ ref. 1909030 


\section{Introducción}

La industria manufacturera, maquiladora y de servicios de exportación concentrada en el norte del país ha transformado las particularidades económicas de los municipios con frontera internacional. La información económica al año 2013 indica que del total de los territorios colindantes con Estados Unidos de América (80 municipios), solo ocho explican más de tres cuartas partes de la producción bruta total fronteriza (Instituto Nacional de Estadística y Geografía [Inegi], 2014). El bloque integrado por Tijuana, Mexicali, Nogales, Ciudad Juárez, Piedras Negras, Reynosa, Nuevo Laredo y Matamoros ha consolidado su fuerza productiva.

En el caso particular de Reynosa, Tamaulipas, el débil desempeño de las industrias no manufactureras ha diluido todo indicio de diversificación económica; se trata de un sistema con escasos encadenamientos intersectoriales, en particular con el de mayor desempeño: fabricación de equipo de cómputo y componentes electrónicos. En situaciones ideales de compra-venta de insumos intersectoriales (tipo Walras), la especialización manufacturera explicaría un comportamiento mercantil caracterizado por influir en el crecimiento económico del resto de las actividades productivas. Si bien, se identifican algunas contribuciones que dan cuenta del perfil económico regional, se adolece de una revisión sistemática de encadenamientos sectoriales; bajo este contexto, la aplicación del modelo de insumo-producto resulta esencial para examinar el funcionamiento del entramado productivo local.

Lo anterior expuesto abre dos interrogantes clave: 1) teniendo en cuenta el comportamiento sectorial nacional, ¿qué subsectores de la economía se concentraron en este municipio al final del periodo de estudio (2013)? Derivado de lo anterior, 2) ¿cuáles de esos subsectores mostraron las mayores interrelaciones productivas por su capacidad de entretejer una red de compra-venta en la economía local?

En este sentido, el objetivo de la presente investigación consiste en determinar las interdependencias productivas entre las diversas actividades económicas del municipio fronterizo de Reynosa (Véase Figura 1). Con los resultados se busca brindar la posibilidad de mejorar la articulación industrial al clasificar los subsectores de acuerdo con la relevancia de sus encadenamientos, para ello se utilizaron diferentes aplicaciones que forman parte de las técnicas de análisis económico regional, específicamente, de los modelos de Leontief $(1936 ; 1941)$.

A lo largo del documento, se expone la conveniencia de estimar una matriz de insumo-producto regional y sus correspondientes multiplicadores contables. La regionalización se elaboró con base en Flegg, Webber y Elliot (1995; Flegg y Webber, 1997), mientras que para el análisis de encadenamientos productivos se tomó como referencia el modelo de Rasmussen (1956).

Se espera que la metodología empleada en la presente investigación sirva de insumo a futuros estudios relacionados con el análisis de interdependencias sectoriales a nivel municipal, así como para el diseño de políticas públicas en materia de desarrollo económico regional. 
Figura 1: Ubicación geográfica del municipio de Reynosa

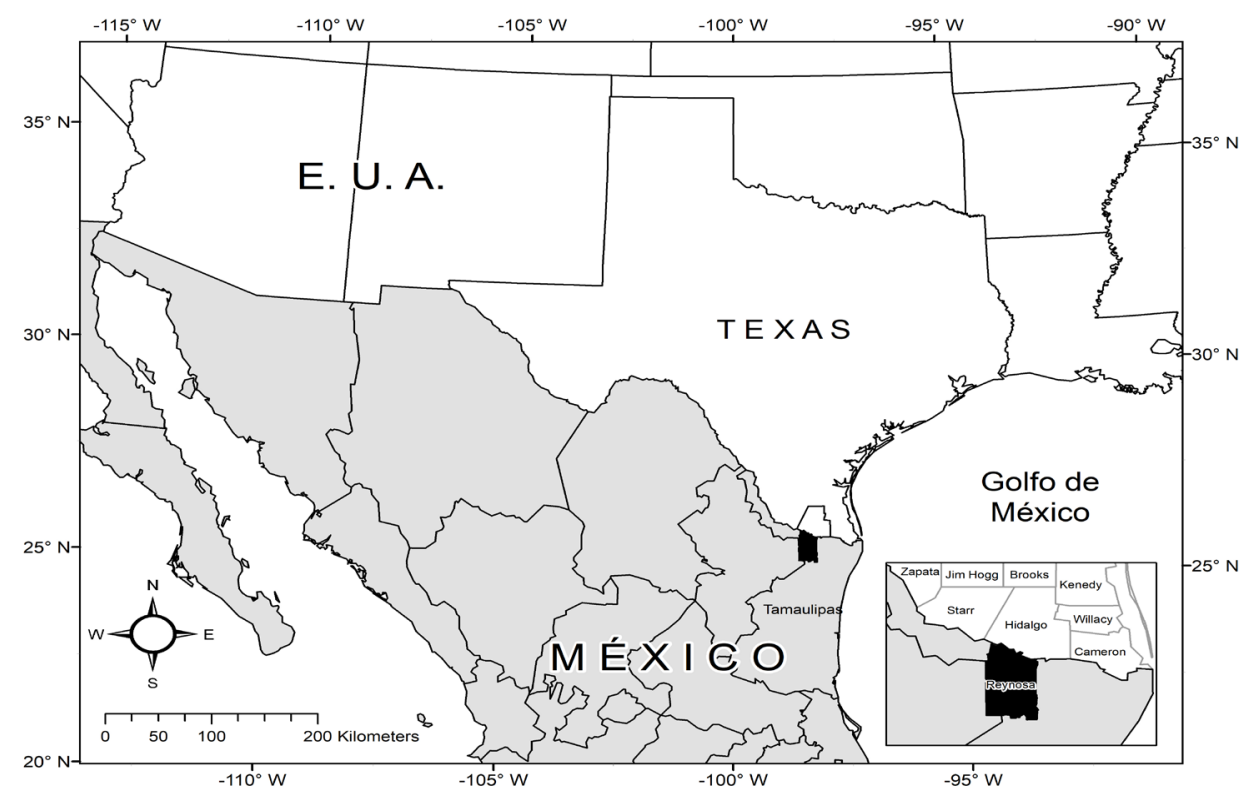

Fuente: Sistema de Información Geográfica (SIG) de El Colegio de Tamaulipas (Coltam).

\section{Anclaje teórico del flujo circular de interdependencias productivas en una economía}

De acuerdo con Miller y Blair (2009), la idea de desarrollar explícitamente la contabilidad de la actividad interindustrial se remonta a 1758 con el economista francés Quesnay (1759), quién representó la economía como un flujo circular de ingreso y producción entre diferentes sectores económicos, mediante su tabla económica. Posteriormente, en los siglos xix y xx, Walras (1874), Pareto (1906), Bortkiewicz (1907) y Cassel (1924) refinaron las ideas de Quesnay al desarrollar el concepto de equilibrio general. Bajo este contexto, en 1928 Leontief (alumno de Bortkiewicz) formalizó estos planteamientos en su tesis doctoral titulada: "La economía nacional como un proceso circular". El citado autor llevó la teoría de equilibrio general hacia una implementación empírica, a través de un sistema insumo-producto de dos sectores que permite relacionar la oferta y la demanda en una economía. En consecuencia, el modelo de Leontief $(1936 ; 1941)$ se consolidó en la segunda mitad del siglo pasado mediante las recomendaciones de la Organización de las Naciones Unidas en términos de la construcción de sistemas de cuentas nacionales (Organización de las Naciones Unidas [ONU], 2018). En la actualidad, el análisis de insumo-producto de Leontief prevalece como uno de los métodos más utilizados en economía; las principales aplicaciones se encuentran alrededor de la estabilidad proporcional de las transacciones intersectoriales (coeficientes técnicos), la elaboración de matrices regionales y los modelos de equilibrio general (Aroche, 2013).

En virtud a lo anterior, el modelo de Leontief $(1936 ; 1941)$ ha generado dos vertientes de análisis: estática y dinámica. Si bien, el primer caso (empleado en este trabajo) es considerado una de las herramientas más útiles para el análisis económico 
regional y sectorial, no logra predecir cambios en los componentes de la demanda final debido a que los multiplicadores registran efectos atemporales sobre la producción. De ahí que la versión dinámica este siendo considerada como una alternativa para resolver estas limitantes (Fuentes, Brugués y González, 2015; Fuentes y Castillo, 2012; Johnson, 1986). El planteamiento considera que algunos insumos contribuyen al proceso de producción pero no son inmediatamente utilizados durante el proceso, siendo necesaria la incorporación de bienes de capital para explicar el crecimiento de la producción (Miller y Blair, 2009). Empero, los métodos de solución incluyen la utilización de un software especializado para la resolución de problemas de optimización dinámica y van más allá del alcance del presente documento.

\section{Del modelo de Leontief a la flexibilización de Flegg}

Inicialmente, las matrices regionales se construyeron mediante el levantamiento de encuestas (métodos directos). Sin embargo, con la finalidad de acortar los tiempos y de reducir los costos de instrumentación, se desarrollaron técnicas alternativas (métodos indirectos y métodos híbridos) ${ }^{1}$ para la construcción de tablas de insumo-producto.

De entre los métodos indirectos basados en coeficientes de localización, el planteamiento de Flegg et al. (1995; Flegg y Webber, 1997) es considerado el más preciso para generar coeficientes regionales a partir de su contraparte nacional, independientemente de la discusión alrededor del valor del parámetro delta (Bonfiglio, 2005; Bonfiglio y Chelli, 2008; Kronenberg, 2011). Al respecto Flegg y Tohmo (2011) señalaron un valor igual a 0.25 como el más conveniente para estimar multiplicadores regionales.

En México, habrá de tomarse en cuenta que el Inegi detuvo la generación de matrices nacionales de insumo-producto desde la década de los años ochenta del siglo pasado (Aroche, 2013). No obstante, en los años 2008 y 2013 dicho instituto presentó matrices nacionales para 2003 y 2008, respectivamente, y en enero del 2018 publicó la matriz de insumo-producto para la economía mexicana del año 2013. En consecuencia, recientemente se ha puesto atención en la elaboración empírica de matrices de insumo-producto regional mediante métodos indirectos basados en coeficientes de localización (Albornoz, Canto y Becerril, 2012; Castro, 2010; Chapa et al., 2009; Chiquiar, Alvarado, Quiroga y Torre, 2017; Dávila, 2002; Fuentes, 2005; González, Díaz y Leal, 2010; Valdés, 2014). De forma similar, el modelo regional constituye una base práctica para el análisis de efectos multiplicadores y encadenamientos productivos a nivel municipal (Fuentes, 2003; Martínez y Gómez, 2008; Salinas, González, León y Rodríguez, 2017; Tapia, Vite, Salazar y Zamora, 2010).

Una de las investigaciones que sobresalen a escala subnacional, es la de Fuentes (2003) quién estimó encadenamientos insumo-producto en el municipio fronterizo de Mexicali, Baja California. Para la estimación de la matriz insumo-producto (MIP) municipal utilizó un método indirecto sintético (el ajuste oferta-demanda) que consiste en la modificación de los coeficientes de la MIP estatal para producir estimaciones de los coeficientes de la MIP municipal. El citado autor consideró que

\footnotetext{
${ }^{1}$ Incorporan información superior (cuantitativa y cualitativa) proveniente de fuentes oficiales, encuestas parciales especializadas y opinión de expertos en el área, además de un procedimiento matemático para balancear los datos externos (Bravo y Castro, 2006; Chapa, Ayala y Hernández, 2009; Fuentes, 2005).
} 
las transacciones interindustriales tienen un patrón igual a las estatales y de este modo calculó la demanda y oferta regional de bienes y servicios. Al ser Mexicali un municipio con vocación histórica agropecuaria, el procedimiento empleado para estimar interdependencias productivas resultó idóneo, toda vez que la actividad del sector no manufacturero es clave en el entramado económico de dicho municipio. En el caso del perfil económico de Reynosa, eminentemente manufacturero, y a falta de una MIP estatal, se considera pertinente el uso de un método indirecto basado en coeficientes de localización para estimar coeficientes técnicos regionales.

Así las cosas, el mayor desafío para los investigadores que aplican técnicas de análisis económico regional al identificar interdependencias productivas, consiste en adecuar el modelo de Leontief $(1936 ; 1941)$ a partir de la flexibilización prevista por Flegg et al. (1995; Flegg y Webber, 1997).

En nuestro caso, se empleó la matriz nacional de insumo-producto del año 2013 (Inegi, 2018), la cual está conformada por 20 sectores, 79 subsectores, 262 ramas y 822 clases económicas y sus valores se encuentran en millones de pesos del 2013.

En el presente trabajo se utilizó un nivel de desagregación de 50 subsectores económicos, por no ser compatible la información proveniente del censo económico a escala nacional y municipal, ejemplo de ello es la ausencia de datos referentes al sector agropecuario; de manera que, trabajar con un nivel mayor de desagregación sectorial (rama o clase) aumentaría el sesgo generado por la escasez de información a escala subnacional.

Por lo que respecta a la regionalización de la MIP nacional, se derivaron los coeficientes municipales de comercio intersectorial mediante la fórmula $F L Q$ presente en Flegg et al. (1995; Flegg y Webber, 1997), con un valor para el parámetro delta igual a 0.25 . Siguiendo a Miller y Blair (2009), debido a la no disponibilidad del vector de producto interno bruto total, se utilizó el vector de Personal Remunerado Total (Inegi, 2014). Con ese mismo vector además del PIB nacional se estimó la estructura de la producción bruta municipal y, finalmente, a través del álgebra matricial se generó la matriz de transacciones intersectoriales para la economía reynosense. ${ }^{2}$

\section{Metodología}

\section{Modelo básico de insumo-producto}

Siguiendo a Miller y Blair (2009), mediante el uso de notación matricial se puede proporcionar una síntesis del modelo de Leontief:

$A X+Y=X$

Donde:

$A=$ Es la matriz de coeficientes técnicos de producción $\left(\mathrm{a}_{\mathrm{i}^{\prime} \mathrm{j}}\right)$.

$X=$ Vector columna de valores brutos de la producción.

$Y=$ Vector columna de demanda final.

\footnotetext{
${ }^{2}$ Por razones de espacio, los resultados provenientes de aplicar el modelo interregional de Leontief para el municipio de Reynosa se presentan en anexos no incluidos aquí; de tal forma que el lector interesado puede solicitar a los autores las bases de datos que sostienen los resultados y que dan origen a los multiplicadores de insumo-producto contenidos en la Tabla 2
} 
Cada coeficiente técnico se calcula de la siguiente forma:

$$
\mathrm{a}_{\mathrm{i}^{\prime} \mathrm{j}}=\mathrm{x}_{\mathrm{i}^{\prime} \mathrm{j}} / \mathrm{x}_{\mathrm{j}} \quad(\mathrm{i}, \mathrm{j}=1,2, \ldots, \mathrm{n})
$$

Donde:

$\mathrm{x}_{\mathrm{i}, \mathrm{j}}=$ Valor de las ventas de insumos intermedios del sector $i$ al $j$.

$\mathrm{x}_{\mathrm{j}}=$ Valor bruto de la producción del sector $j$.

Despejando Y:

$Y=X(I-A)$

Donde:

$I=$ Matriz identidad.

$(I-A)=$ Matriz de Leontief.

Para resolver $X$, se multiplica $(I-A)^{-1}$, la inversa de la matriz de Leontief, por $Y$.

$X=(I-A)^{-1} Y$

Los insumos necesarios para la solución de este sistema son los coeficientes técnicos de producción $\left(a_{i, j}\right)$ y los valores del vector de demanda final $(Y)$. Si se conocen $(X)$ y $\left(a_{i, j}\right)$, directamente pueden obtenerse los valores de $(Y)$ :

$Y=X(I-A)$

\section{Regionalización del modelo insumo-producto}

El propósito es encontrar un estimador $\left(\mathrm{t}_{\mathrm{i}_{\mathrm{j}}}\right)$ del porcentaje de los coeficientes técnicos de producción $\left(\mathrm{a}_{\mathrm{i}^{\prime} \mathrm{j}}\right)$ abastecido en el interior de la propia región. A su vez, el conocimiento de dicho estimador permite calcular los coeficientes regionales de comercio intersectorial $\left(\mathrm{r}_{\mathrm{i}^{\prime} \mathrm{j}}\right)$, estos últimos expresados en los siguientes términos:

$$
r_{i, j}=t_{i, j} a_{i, j} \quad(i, j=1,2, \ldots, n)
$$

La fórmula propuesta por Flegg et al. (1995; Flegg y Webber, 1997) para encontrar el estimador $\left(\mathrm{t}_{\mathrm{i}, \mathrm{j}}\right)$ del porcentaje de los coeficientes técnicos de producción $\left(\mathrm{a}_{\mathrm{i}, \mathrm{j}}\right)$ abastecido en el interior de la propia región, es la siguiente:

$$
F L Q_{i, j}=C I L Q_{i, j} \lambda_{r}^{\delta} \quad i, j=1,2, \ldots, n
$$

Donde:

$F L Q_{i, j}=$ Coeficiente de Flegg et al. (1995; Flegg y Webber, 1997).

$C I L Q_{i, j}=$ Coeficientes de localización de industria cruzada.

$\lambda_{r}^{\delta}=$ Factor de ponderación del tamaño relativo de la región $(r)$. 
Por su parte:

$$
\begin{array}{rl}
\mathrm{CILQ}_{\mathrm{i}, \mathrm{j}}=L Q_{i} / L Q_{\mathrm{j}} & i, j=1,2, \ldots, n \\
L Q_{i}=\left(P R T_{i, r} / P R T_{r}\right) /\left(P R T_{i} / P R T\right) & i, r=1,2, \ldots, n \\
\lambda_{\mathrm{r}}^{\delta}=\log _{2}\left[1+\left(P R T_{r} / P R T\right)\right] & r=1,2, \ldots, n
\end{array}
$$

Donde:

$l q_{i} ; l q_{j}=$ Coeficientes de localización simples.

$P R T=$ Producto Remunerado Total.

Una vez obtenido el valor de los $t_{i, j}$, al multiplicarlos por el correspondiente coeficiente nacional $\left(\mathrm{a}_{\mathrm{i}, \mathrm{j}}\right)$, se estiman los coeficientes regionales de comercio intersectorial $\left(\mathrm{r}_{\mathrm{i}, \mathrm{j}}\right)$.

A su vez, el modelo regional de insumo-producto se formula y resuelve de manera análoga al modelo básico. De acuerdo con Dávila (2015), la solución se expresa en los siguientes términos:

$X^{r}=\left(I-A^{r r}\right)^{-1} Y^{r}$

Donde:

$A^{r r}=$ Es la matriz de coeficientes regionales de comercio intersectorial ( $r i j$ ).

$X^{r}=$ Vector columna de valores brutos de la producción de la región $r$.

$I=$ Matriz identidad.

$\left(I-A^{r}\right)=$ Matriz de Leontief del modelo regional. ${ }^{3}$

Los flujos interregionales domésticos se obtienen de forma residual entre el total de insumos domésticos de la MIP nacional y aquellos ofertados dentro de la región. En notación matricial, tenemos:

Donde:

$$
A=\left[\begin{array}{ll}
A^{r r} & A^{r s} \\
A^{s r} & A^{s s}
\end{array}\right]
$$

$A^{r r}=$ Matriz de coeficientes regionales de la región $r$.

$A^{s r}=$ Matriz de coeficientes de importaciones interregionales de insumos domésticos de $r$ al resto del país (región $s$ ).

$A^{r s}=$ Matriz de coeficientes de exportaciones interregionales de insumos domésticos de $r$ a $s$.

$A^{s s}=$ Matriz de coeficientes regionales de la región $s$.

${ }^{3}$ Se aclara que para la estimación de los resultados presentados en este trabajo, el análisis se acotó a la matriz de coeficientes regionales de comercio intersectorial $A^{r r}$. 


$$
X=\left[\begin{array}{c}
X^{r} \\
X^{s}
\end{array}\right]
$$

Donde:

$X^{r}=$ Vector columna de valores brutos de la producción de la región $r$.

$X^{s}=$ Vector columna de valores brutos de la producción de la región $s$.

Donde:

$$
Y=\left[\begin{array}{l}
Y^{r} \\
Y^{s}
\end{array}\right]
$$

$Y^{r}=$ Vector columna de demanda final de la región $r$.

$Y^{s}=$ Vector columna de demanda final de la región $s$.

$$
I=\left[\begin{array}{ll}
I^{r} & O \\
O & I^{5}
\end{array}\right]
$$

Donde:

$r=$ Matriz identidad de $r$.

$I^{s}=$ Matriz identidad de $s$.

La solución del sistema se obtiene como en el modelo estándar.

\section{Los multiplicadores de producción, empleo, remuneración de los asalariados y valor agregado}

Uno de los principales usos que brinda un modelo de insumo-producto consiste en determinar el efecto que tienen los cambios exógenos en la economía. A este proceso se le denomina análisis de impactos $\mathrm{y}$, a las medidas agregadas que se utilizan en el mismo, se les llama multiplicadores de insumo-producto. Los multiplicadores más utilizados son aquellos que estiman los efectos de los cambios exógenos sobre: la producción de las industrias, la remuneración de los asalariados debido al aumento de la producción, el empleo generado en cada industria debido a la nueva producción, y el valor agregado que se crea por cada sector productivo debido al incremento en la producción (Miller y Blair, 2009).

De manera explicativa, el multiplicador de la producción para el sector $j$, se define como el valor total de la producción de todas las industrias de la economía que es necesario para satisfacer la demanda final de la producción del sector $j$, cuando esta aumenta en una unidad monetaria. Los multiplicadores totales "hacia atrás" registran el incremento necesario en el valor bruto de la producción de los distintos sectores de la economía ante un aumento en la demanda final de un sector de actividad; mientras que los multiplicadores totales "hacia adelante" registran el aumento regional en el valor bruto de la producción de un sector para satisfacer un aumento unitario en la demanda final de todos los sectores de la economía local (Miller y Blair, 2009).

Los efectos directos representan la demanda adicional de insumos generada por el aumento en la demanda final sectorial, mientras que los efectos indirectos están formados por la reacción en cadena de todos los sectores económicos, como resultado de la demanda adicional de insumos del sector que modificó su demanda 
final inicialmente. Sin embargo, no todas las actividades económicas tienen la misma capacidad de inducir impactos multiplicadores sobre otras (Dávila, 2015).

Siguiendo a Dávila (2015), la solución del modelo de producción puede expresarse en los siguientes términos:

$$
\begin{aligned}
& x=(I-A)^{-1} y \\
& \text { Si: } \\
& L=(I-A)^{-1} \\
& \text { Entonces: } \\
& x=L y
\end{aligned}
$$

Los elementos de la matriz inversa de Leontief $(L)$ pueden agruparse en cuatro submatrices:

$$
L=\left[\begin{array}{ll}
L_{11} & L_{12} \\
L_{21} & L_{22}
\end{array}\right]
$$

Con base en lo anterior, los multiplicadores totales $(m)$ de producción (subíndice o) de la región analizada (identificada con el superíndice $\mathrm{r}$ ), se obtienen sumando las columnas con los elementos $\left(L_{11} y L_{21}\right)$ de la inversa de Leontief $(L)$ del modelo interregional: ${ }^{4}$

$$
m_{o}^{r}=i,\left[\begin{array}{l}
L_{11} \\
L_{21}
\end{array}\right]
$$

Por su parte, para calcular los multiplicadores totales referentes a empleo $\left(l_{c}\right)$, primero debe computarse una matriz diagonal con los coeficientes de la participación de los puestos de trabajo remunerados en la producción bruta de cada sector. Para ello, se multiplica el vector fila de los puestos de trabajo remunerados por la inversa de una matriz diagonal conformada con los valores de la producción bruta:

$$
l_{c}^{\prime}=l^{\prime} \hat{x}^{-1}
$$

Posteriormente, esta matriz debe multiplicarse por la inversa de Leontief $(L)$ del modelo interregional y el resultado se multiplica por la inversa de la matriz calculada de forma previa:

$$
m_{i}^{I I}=i l_{c}^{\prime} L\left(\hat{\imath}_{c}^{\prime}\right)^{-1}
$$

La sumatoria de las columnas de la matriz resultante muestra los multiplicadores totales del empleo. Finalmente, para calcular los multiplicadores totales del valor agregado y de la remuneración de los asalariados se procede de forma similar,

\footnotetext{
${ }^{4}$ Se aclara que para la estimación de los resultados presentados en este trabajo, el análisis se acotó a la submatriz $\mathrm{L}_{11}$ para mantener la consistencia con la delimitación referente a la matriz $A^{r r}$ mencionada previamente.
} 
sustituyendo en las dos ecuaciones anteriores los valores correspondientes a cada variable (Dávila, 2015). ${ }^{5}$

\section{Análisis de encadenamientos productivos}

El método clásico del análisis estructural se centra en la determinación de los encadenamientos productivos, los cuales cuantifican efectos directos e indirectos, tanto hacia atrás (BLR por sus siglas en inglés) como hacia adelante ( $F L R$ por sus siglas en inglés). Es decir, los encadenamientos permiten identificar los sectores con mayor potencial de arrastre o sectores que se encuentran asociados a muchos otros sectores. Los encadenamientos hacia atrás miden la capacidad que tiene un sector para generar el desarrollo de otros mediante la utilización de sus insumos. Mientras que los encadenamientos hacia adelante tienen lugar, cuando un sector ofrece un producto que es el insumo de otro sector, que a la vez sirve de estímulo para un tercer sector, el cual es insumo del primer sector (Chenery y Watanabe citados en Schuschny, 2005).

Los encadenamientos tienen sus orígenes en los trabajos desarrollados por Chenery y Watanabe (1958), Rasmussen (1956) y Ghosh (1958), quiénes establecieron unaclasificación sectorial cuatripartita. ${ }^{6}$ En donde los sectores se clasifican de la siguiente manera:

- Base: Presentan unos encadenamientos hacia atrás menores que el promedio y hacia delante por encima de la media; estos generan una escasa demanda, pero mucha oferta.

- Impulsores: Demandan insumos de otros sectores intermedios, consecuentemente, generan un estímulo a la producción de bienes intermedios.

- Independientes o aislados: En general son poco atractivos, ya que provocan un menor impacto en la economía, pues su desarrollo no afecta significativamente a los sectores que demandan sus productos, ni a los que los utilizan como productos intermedios.

- Clave: Presentan unos encadenamientos hacia atrás y hacia adelante mayores al promedio; son importantes por la demanda que producen y la oferta que generan en el resto de los sectores.

Particularmente, Rasmussen (1956) sugiere dos medidas basadas en la matriz inversa de Leontief para cuantificar los efectos directos e indirectos hacia atrás (BLR) y hacia adelante (FLR) que puede experimentar un sector. Las medidas normalizadas se obtienen a partir de las expresiones (Tabla 1):

\footnotetext{
${ }^{5}$ Los multiplicadores de remuneración de asalariados y valor agregado se obtienen a partir de la información de remuneración de asalariados y valor agregado bruto respectivamente, de acuerdo a la MIP nacional base 2013.

${ }^{6}$ No se desconoce que existen técnicas alternativas para calcular interdependencias productivas y establecer clasificaciones sectoriales, tanto en economías nacionales como en subnacionales, tal es el caso del método de extracción hipotética de Dietzenbacher, Linden y Steenge (1993) y la teoría de redes. En el primer enfoque sobresalen los trabajos de Chraki (2016) y Llano (2009), mientras que el segundo se ha configurado a partir de diversas contribuciones, entre las que destaca el trabajo seminal de García y Ramos (2003), así como las aplicaciones de Hurtado y Martínez (2017), Molina y Gutiérrez (2015) y Fuentes, Cárdenas y Brugués (2013).
} 
$B L R=\left(n i^{\prime}(I-A)^{-1}\right) /\left(i^{\prime}(I-A)^{-1} i\right)$

$F L R=\left(n(I-A)^{-1} i\right) /\left(i \cdot(I-A)^{-1} i\right)$

Donde:

$(I-A)^{-1}$ : es la matriz inversa de Leontief.

$i$ : es un vector fila con valores iguales a la unidad.

A: es la matriz de coeficientes técnicos.

$i$ : es un vector columna con valores iguales a uno.

$n$ : es el número total de sectores.

Tabla 1: Clasificación sectorial de acuerdo a sus encadenamientos: Efectos BLR y FLR según Rasmussen (1956)

\begin{tabular}{|c|c|c|}
\hline & BL $<\mathbf{1}$ & BL $>\mathbf{1}$ \\
\hline FL $<\mathbf{1}$ & Independiente & Impulsor \\
\hline FL $>\mathbf{1}$ & Base & Clave \\
\hline
\end{tabular}

Fuente: Elaboración propia a partir de Rasmussen (1956).

\section{Resultados}

\section{Hacia la construcción de la matriz insumo-producto de Reynosa 2013: Contexto de partida}

Con la finalidad de especificar la composición de la estructura industrial de la economía reynosense, en esta sección se incorporan algunas técnicas de análisis económico regional, entre ellas: la tasa media de crecimiento anual del producto bruto total, los coeficientes de localización del personal remunerado total, los multiplicadores de insumo-producto y el análisis de los encadenamientos productivos.

\section{Tasa media de crecimiento anual referente al producto bruto total}

La frontera norte se conforma por seis estados de la República mexicana. En conjunto representan $24 \%$ de la producción bruta total de México. En cuanto a los municipios fronterizos, hay 80 colindantes con el vecino país del norte, de entre ellos destacan ocho que concentran $18 \%$ de la producción de los estados fronterizos (por ende, la aportación de los 72 municipios restantes es poco significativa). De manera que los municipios de Tijuana, Mexicali, Nogales, Ciudad Juárez, Piedras Negras, Reynosa, Nuevo Laredo y Matamoros explican más de tres cuartas partes de la producción bruta total fronteriza (Inegi, 2014).

$\mathrm{Al}$ examinar la tasa media de crecimiento anual (TMCA) del producto bruto total (РВT) de los municipios fronterizos más relevantes para el periodo 2003-2013, ${ }^{7}$ se destaca

\footnotetext{
${ }^{7}$ El análisis de la TMCA del PBT se basa en la información de los censos económicos publicados por el Inegi $(2004 ; 2014)$.
} 
Piedras Negras, Coahuila (9.7\%) como el de mayor desempeño; enseguida Reynosa $(6.79 \%)$, que presentó un valor muy similar a los registrados por Tijuana $(6.51 \%)$ y Nuevo Laredo (5.79\%). El valor estimado de Reynosa sobrepasó el crecimiento de Nogales (5.18\%), Mexicali (4.94\%), Ciudad Juárez (3.49\%) y Matamoros (2.64\%).

En contraste, al examinar la relación entre la TMCA y la participación municipal en el PBT nacional, en donde, Tijuana (1.13\%) y Ciudad Juárez (0.99\%) destacaron como los municipios fronterizos con la mayor contribución, se constata que Reynosa $(0.85 \%)$ y Mexicali $(0.75 \%)$ también forman parte de este grupo de municipio sobresalientes. Dicho bloque superó ampliamente el comportamiento mostrado por Matamoros $(0.26 \%)$, Nuevo Laredo $(0.21 \%)$, Piedras Negras $(0.13 \%)$ y Nogales $(0.13 \%)$ (Véase Figura 2).

Figura 2: Municipios fronterizos de México: Tasas medias de crecimiento anual del producto interno bruto (2003-2013) y participación en el producto bruto total nacional (2013). Porcentajes

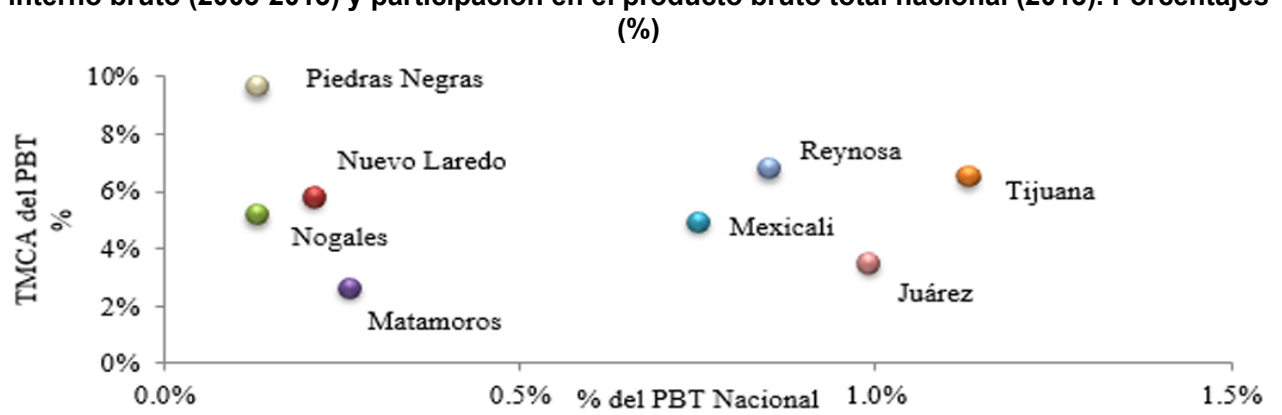

Fuente: Elaboración propia con información de Inegi (2004; 2014).

La relación entre TMC del PBT municipal y participación en el PBT nacional deja entrever que Reynosa constituye un territorio de inversión ampliamente considerado por las empresas en su decisión por localizarse, y es que dentro de los municipios fronterizos, Reynosa se considera el más importante en la región noreste. Lo anterior expuesto abre dos interrogantes clave: 1) teniendo en cuenta el comportamiento sectorial nacional ¿qué subsectores de la economía se aglutinaron en este municipio al final del periodo de estudio (2013)? y 2) ¿cuáles de esos subsectores mostraron las mayores interrelaciones productivas al tener una mayor capacidad para entretejer una red de compra-venta en la economía local? Para dar respuesta a la primera pregunta se utilizó la herramienta de coeficientes de localización, mientras que para la segunda interrogante se construyó una matriz insumo-producto interregional para el municipio de Reynosa con base en Flegg et al. (1995; Flegg y Webber, 1997).

\section{Coeficientes de localización}

Continuando con el análisis, se emplean los Coeficientes de Localización ${ }^{8}$ (LQ por sus siglas en inglés) para explorar la evolución de la estructura económica municipal

${ }^{8}$ La fórmula para estimar el coeficiente de localización se expresa de la siguiente forma: LQi = ((ei / et) / (Ei / Et)). Donde, "e" es el personal remunerado total regional (Reynosa), "E" es el personal remunerado total nacional, "i" se refiere al subsector de actividad económica y "t" se refiere a la economía total. 
e identificar la importancia relativa de cada sector económico en términos de producción. El Coeficiente de Localización (LQ) es idóneo para contrastar el peso de un sector en la región (Reynosa) contra el peso de ese mismo sector en una economía de referencia (México), mediante tres posibles resultados: fuerte presencia regional $(\mathrm{LQ}>1)$, débil presencia regional $(\mathrm{LQ}<1)$ y autosuficiencia $(\mathrm{LQ}=1)$.

En la Figura 3 se registran los coeficientes de localización de Reynosa para el año 2003 y 2013. Es muy claro que el sector de fabricación de equipo de cómputo y componentes electrónicos es el más localizado en el municipio, al que se le añaden las actividades relacionadas con la extracción de petróleoy gas al mostrar una concentración importante en términos de personal remunerado. Lo anterior se confirma por la escasa presencia regional de la mayoría de los subsectores correspondientes a la economía terciaria, con excepción de los servicios de autotransporte de carga.

Figura 3: Reynosa: Coeficientes de Localización (LQi) 2003 y 2013
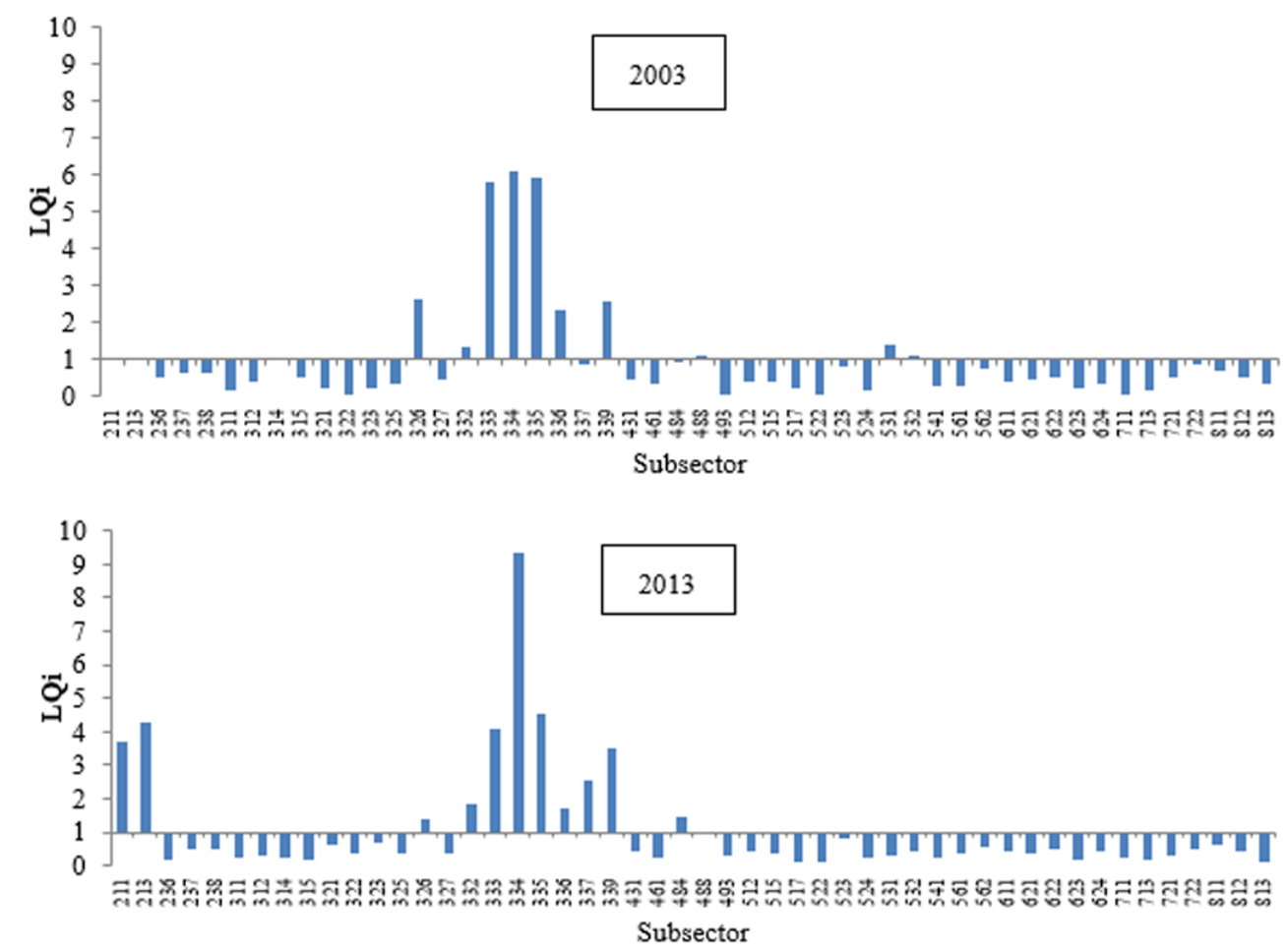

Fuente: Elaboración propia con información de Inegi (2014).

Nota 1: La nomenclatura del subsector correspondiente se puede consultar en la Tabla 2.

Nota 2: La base de datos del año 2003 no contiene información referente al personal remunerado total del municipio de Reynosa para los subsectores 211,213 y $314 .{ }^{9}$

${ }^{9}$ Debido a la no disponibilidad del vector sectorial de producto interno bruto, siguiendo a Miller y Blair (2009) se utilizó información sectorial referente al personal remunerado total para calcular los coeficientes de localización. Los datos refieren a los años 2003 y 2013, y provienen del censo económico realizado por el Inegi $(2004 ; 2014)$. La elección de la variable de personal remunerado total, se realizó para evitar inconsistencias entre los coeficientes de localización y el método indirecto empleado para regionalizar la MIP nacional. 
Antes de proseguir con el modelo interregional de insumo-producto, se constata, mediante los coeficientes de localización, que la industria manufacturera, maquiladora y de servicios de exportación consolida su especialización desde el año 2003, esto al mantener su hegemonía tanto en la fabricación de computadoras y equipo periférico como en la fabricación de motores y generadores eléctricos (Dávila y Escamilla, 2013; Esqueda, 2018; Esqueda y Trejo, 2014; Pérez, Ceballos y Cogco, 2012). ${ }^{10}$

\section{Modelo interregional de insumo-producto}

En esta sección se analizan los multiplicadores de la producción (efecto multiplicador) y los multiplicadores totales (efecto multiplicador ponderado) de los principales agregados macroeconómicos: remuneración de los asalariados, empleo y valor agregado. Los resultados se presentan de forma resumida en la Tabla 2.

Tabla 2: Reynosa: Multiplicadores ponderados (producción bruta, empleo, remuneración de los asalariados y valor agregado)

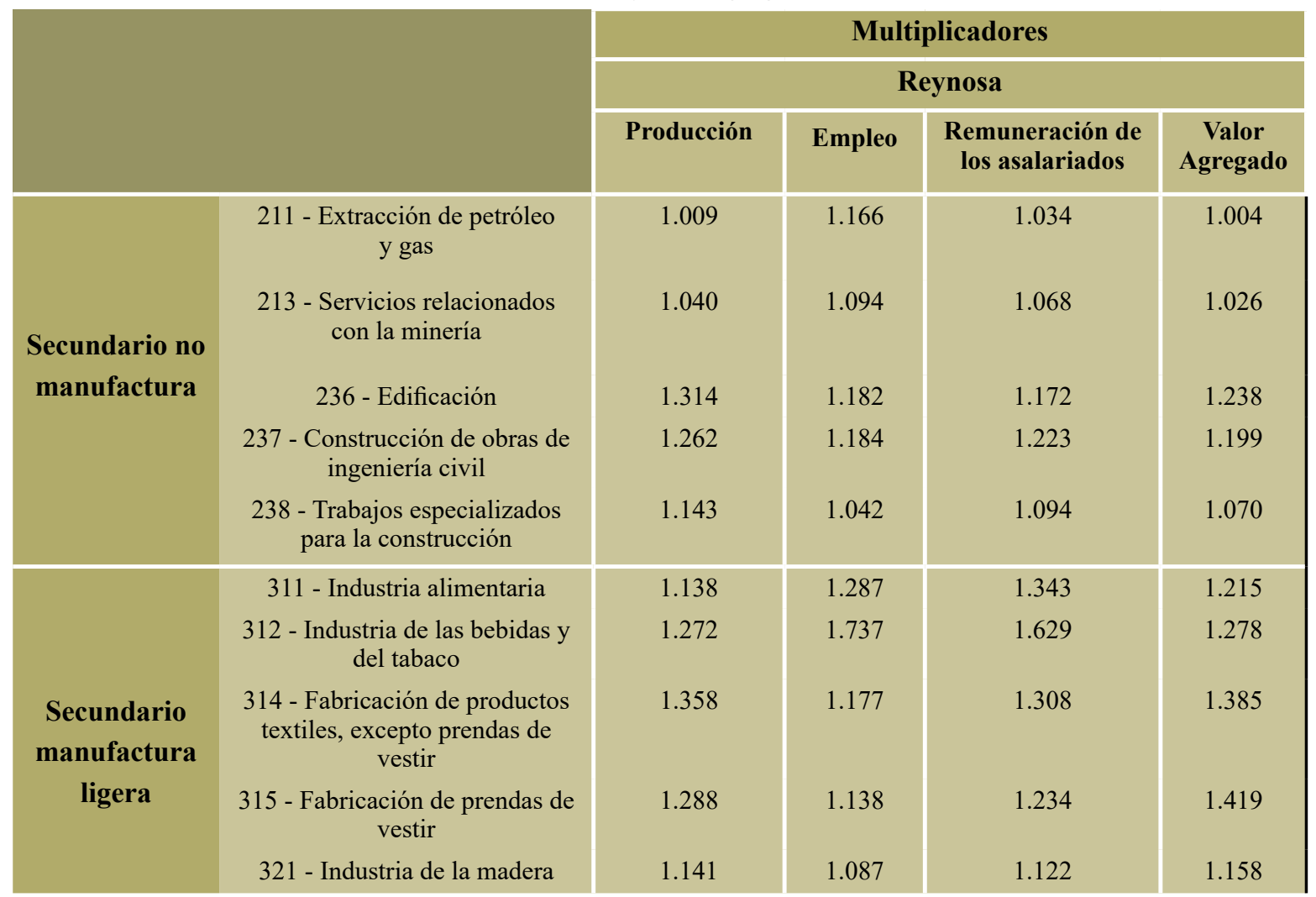

\footnotetext{
${ }^{10}$ La condición procíclica de la manufactura advierte contracciones importantes, tal fue el caso de la industria electrónica instalada en Reynosa. Las cifras muestran que del año 2008 al 2013, los puestos de trabajo disminuyeron de 42232 a 33 392, además, decreció el valor de su producción bruta al pasar de 11 mil millones a 9 mil millones de pesos (Inegi, 2009; 2014).
} 


\begin{tabular}{|c|c|c|c|c|c|}
\hline & $\begin{array}{l}322 \text { - Industria del papel } \\
323 \text { - Impresión e industrias } \\
\text { conexas }\end{array}$ & $\begin{array}{l}1.230 \\
1.252\end{array}$ & $\begin{array}{l}1.417 \\
1.188\end{array}$ & $\begin{array}{l}1.367 \\
1.244\end{array}$ & $\begin{array}{l}1.392 \\
1.312\end{array}$ \\
\hline \multirow{10}{*}{$\begin{array}{c}\text { Secundario } \\
\text { manufactura } \\
\text { pesada }\end{array}$} & 325 - Industria química & 1.252 & 1.823 & 1.377 & 1.530 \\
\hline & $\begin{array}{l}326 \text { - Industria del plástico } \\
\text { y del hule }\end{array}$ & 1.168 & 1.179 & 1.194 & 1.216 \\
\hline & $\begin{array}{l}327 \text { - Fabricación de productos a } \\
\text { base de minerales no metálicos }\end{array}$ & 1.189 & 1.327 & 1.360 & 1.332 \\
\hline & $\begin{array}{c}332 \text { - Fabricación de productos } \\
\text { metálicos }\end{array}$ & 1.178 & 1.164 & 1.195 & 1.189 \\
\hline & $\begin{array}{c}333 \text { - Fabricación de maquinaria } \\
\text { y equipo }\end{array}$ & 1.364 & 1.369 & 1.350 & 1.304 \\
\hline & $\begin{array}{l}334 \text { - Fabricación de equipo de } \\
\text { computación, comunicación, } \\
\text { medición y de otros equipos, } \\
\text { componentes y accesorios } \\
\text { electrónicos }\end{array}$ & 2.130 & 2.161 & 2.137 & 2.177 \\
\hline & $\begin{array}{l}335 \text { - Fabricación de accesorios, } \\
\text { aparatos eléctricos y equipo de } \\
\text { generación de energía eléctrica }\end{array}$ & 1.455 & 1.429 & 1.452 & 1.448 \\
\hline & $\begin{array}{c}336 \text { - Fabricación de equipo de } \\
\text { transporte }\end{array}$ & 1.426 & 1.804 & 1.740 & 1.461 \\
\hline & $\begin{array}{l}337 \text { - Fabricación de muebles, } \\
\text { colchones y persianas }\end{array}$ & 1.082 & 1.050 & 1.066 & 1.085 \\
\hline & $\begin{array}{c}339 \text { - Otras industrias } \\
\text { manufactureras }\end{array}$ & 1.307 & 1.189 & 1.235 & 1.263 \\
\hline \multirow{9}{*}{$\begin{array}{l}\text { Actividades } \\
\text { terciarias }\end{array}$} & $\begin{array}{c}431 \text { - Comercio al por mayor de } \\
\text { abarrotes, alimentos, bebidas, } \\
\text { hielo y tabaco }\end{array}$ & 1.085 & 1.273 & 1.509 & 1.048 \\
\hline & $\begin{array}{c}461 \text { - Comercio al por menor de } \\
\text { abarrotes, alimentos, bebidas, } \\
\text { hielo y tabaco }\end{array}$ & 1.101 & 1.103 & 1.102 & 1.065 \\
\hline & 484 - Autotransporte de carga & 1.078 & 1.056 & 1.052 & 1.042 \\
\hline & $\begin{array}{l}488 \text { - Servicios relacionados con } \\
\text { el transporte }\end{array}$ & 1.158 & 1.177 & 1.133 & 1.087 \\
\hline & $\begin{array}{l}493 \text { - Servicios de almace- } \\
\text { namiento }\end{array}$ & 1.624 & 1.252 & 1.361 & 1.448 \\
\hline & $\begin{array}{l}512 \text { - Industria fílmica y del } \\
\text { video, e industria del sonido }\end{array}$ & 1.209 & 1.479 & 1.641 & 1.204 \\
\hline & 515 - Radio y televisión & 1.327 & 3.749 & 3.273 & 1.375 \\
\hline & 517 - Telecomunicaciones & 1.419 & 2.785 & 1.523 & 1.210 \\
\hline & $\begin{array}{c}522 \text { - Instituciones de interme- } \\
\text { diación crediticia y financiera } \\
\text { no bursátil }\end{array}$ & 1.223 & 3.048 & 1.384 & 1.223 \\
\hline
\end{tabular}




\begin{tabular}{|c|c|c|c|c|c|}
\hline & $\begin{array}{l}523 \text { - Actividades bursátiles, } \\
\text { cambiarias y de inversión } \\
\text { financiera }\end{array}$ & 1.062 & 1.410 & 1.075 & 1.068 \\
\hline & $\begin{array}{l}524 \text { - Compañías de fianzas, } \\
\text { seguros y pensiones }\end{array}$ & 1.190 & 2.607 & 1.759 & 1.337 \\
\hline & 531 - Servicios inmobiliarios & 1.028 & 1.158 & 1.203 & 1.015 \\
\hline & $\begin{array}{c}532 \text { - Servicios de alquiler de } \\
\text { bienes muebles }\end{array}$ & 1.206 & 1.256 & 1.389 & 1.123 \\
\hline & $\begin{array}{l}541 \text { - Servicios profesionales, } \\
\text { científicos y técnicos }\end{array}$ & 1.151 & 1.227 & 1.132 & 1.109 \\
\hline & $\begin{array}{l}561 \text { - Servicios de apoyo a los } \\
\text { negocios }\end{array}$ & 1.047 & 1.010 & 1.012 & 1.025 \\
\hline & $\begin{array}{c}562 \text { - Manejo de residuos } \\
\text { y desechos, y servicios de } \\
\text { remediación }\end{array}$ & 1.188 & 1.108 & 1.141 & 1.133 \\
\hline & 611 - Servicios educativos & 1.039 & 1.020 & 1.008 & 1.020 \\
\hline $\begin{array}{l}\text { Actividades } \\
\text { terciarias }\end{array}$ & $\begin{array}{l}621 \text { - Servicios médicos de } \\
\text { consulta externa y servicios } \\
\text { relacionados }\end{array}$ & 1.127 & 1.080 & 1.035 & 1.083 \\
\hline & 622 - Hospitales & 1.151 & 1.109 & 1.038 & 1.106 \\
\hline & $\begin{array}{c}623 \text { - Residencias de asistencia } \\
\text { social y para el cuidado de la } \\
\text { salud }\end{array}$ & 1.295 & 1.087 & 1.085 & 1.242 \\
\hline & $\begin{array}{l}624 \text { - Otros servicios de } \\
\text { asistencia social }\end{array}$ & 1.194 & 1.098 & 1.112 & 1.246 \\
\hline & $\begin{array}{c}711 \text { - Servicios artísticos, } \\
\text { culturales y deportivos, y otros } \\
\text { servicios relacionados }\end{array}$ & 1.138 & 1.205 & 1.233 & 1.088 \\
\hline & $\begin{array}{l}713 \text { - Servicios de entretenimien- } \\
\text { to en instalaciones recreativas y } \\
\text { otros servicios recreativos }\end{array}$ & 1.322 & 1.547 & 1.584 & 1.368 \\
\hline & $\begin{array}{c}721 \text { - Servicios de alojamiento } \\
\text { temporal }\end{array}$ & 1.149 & 1.303 & 1.380 & 1.101 \\
\hline & $\begin{array}{l}722 \text { - Servicios de preparación } \\
\text { de alimentos y bebidas }\end{array}$ & 1.114 & 1.042 & 1.063 & 1.087 \\
\hline & $\begin{array}{c}811 \text { - Servicios de reparación y } \\
\text { mantenimiento }\end{array}$ & 1.390 & 1.069 & 1.211 & 1.212 \\
\hline & 812 - Servicios personales & 1.090 & 1.072 & 1.164 & 1.059 \\
\hline & $\begin{array}{l}813 \text { - Asociaciones y } \\
\text { organizaciones }\end{array}$ & 1.178 & 1.126 & 1.112 & 1.143 \\
\hline
\end{tabular}

Fuente: MIP Reynosa, 2013.

Nota 1: Se destacan los resultados en negritas para identificar los cinco valores más altos y en gris claro para los cinco valores más bajos. 
Una vez registrados los dos efectos, se recomienda la lectura de la tabla de multiplicadores ponderados por bloques productivos, es decir, agrupando las actividades económicas de acuerdo con su clasificación sectorial, a saber: $a$ ) secundario no manufactura, $b$ ) secundario manufactura ligera, $c$ ) secundario manufactura pesada y $d)$ actividades terciarias.

\section{Sector secundario no manufactura}

A pesar de que la extracción de petróleo y gas representa una actividad que impulsa la economía por los empleos directos e indirectos que genera, los resultados al año 2013 mostraron que las interdependencias productivas fueron poco influyentes en la economía local, es decir, no mostraron multiplicadores significativos. En contraste, las actividades relacionadas con la construcción (edificación y obras de ingeniería civil) mantuvieron valores por encima del promedio, particularmente, en lo relativo a la producción. En otras palabras, cada peso adicional en el valor de su producción aumenta en 1.3 pesos el producto total del resto de la economía sectorial reynosense.

\section{Secundario manufactura ligera}

Este sector, se conforma por una serie de actividades industriales de elaboración de bienes de consumo que no implica un sucesivo proceso productivo de transformación. De entre las industrias que constituyen el bloque, sobresalió la industria de las bebidas y el tabaco ya que su influencia en la economía local resultó significativa en términos de empleo y remuneración de los asalariados. Por ejemplo, un aumento unitario en el empleo de dicha actividad generaría o derivaría en la creación de 1.7 puestos de trabajo en la economía total de Reynosa; a su vez, un incremento unitario en la remuneración de los asalariados elevaría en 1.6 pesos la remuneración de los asalariados en el resto de las actividades productivas de Reynosa.

\section{Secundario manufactura pesada}

Las actividades con los multiplicadores más grandes de producción se localizaron en la manufactura pesada. En este conjunto la fabricación de equipo de computación, comunicación y accesorios electrónicos figuró como el de mayor dinamismo en los cuatro agregados macroeconómicos bajo estudio. De lo anterior se deduce que por cada empleo añadido en este subsector se adicionan 2.1 puestos de trabajo en el sistema económico local.

Otro subsector dinámico es el de fabricación de equipo de transporte, este se ubicó como uno de las más sobresalientes en términos de producción, remuneración de los asalariados y valor agregado, toda vez que por cada peso añadido al subsector se crean respectivamente 1.4, 1.7 y 1.4 pesos en la economía reynosense total. Mención especial merece el desempeño de la industria química al mostrar multiplicadores por arriba de la media en las cuatro variables macroeconómicas. 


\section{Actividades terciarias}

Cuando en el subsector de radio y televisión se crea un nuevo empleo, el empleo de Reynosa crece en 3.7 puestos de trabajo. Tan pujante es esta industria que al experimentar un incremento unitario en la variable de remuneración de los asalariados, la remuneración de los asalariados en el conjunto de actividades económicas locales aumentan en 3.2 pesos. De forma similar las compañías de fianzas, seguros y pensiones ocuparon una posición relevante en los multiplicadores de empleo y remuneración de los asalariados, lo que pone de manifiesto su capacidad de influir en el comportamiento de la economía local.

Cabe mencionar que los subsectores económicos con los valores más bajos tuvieron lugar dentro del bloque terciario, particularmente en lo que respecta al valor agregado y remuneración de los asalariados, los resultados muestran la escasa influencia que tienen los servicios como estimulantes de la economía de Reynosa. Es importante señalar que en economías desarrolladas el sector terciario es un catalizador preponderante del crecimiento económico debido a sus articulaciones intersectoriales (Berlingieri, 2014).

\section{Encadenamientos productivos}

En la Figura 4 se muestran los resultados de la tipificación sectorial referida a los encadenamientos productivos con base en los criterios de Rasmussen (1956): siete de ellos se clasifican como actividades base, 24 actividades son independientes, ocho se encuentran clasificadas como impulsoras y, finalmente, seis actividades forman parte del grupo de sectores clave.

Figura 4. Reynosa: Clasificación de los subsectores económicos según sus encadenamientos en términos de producción

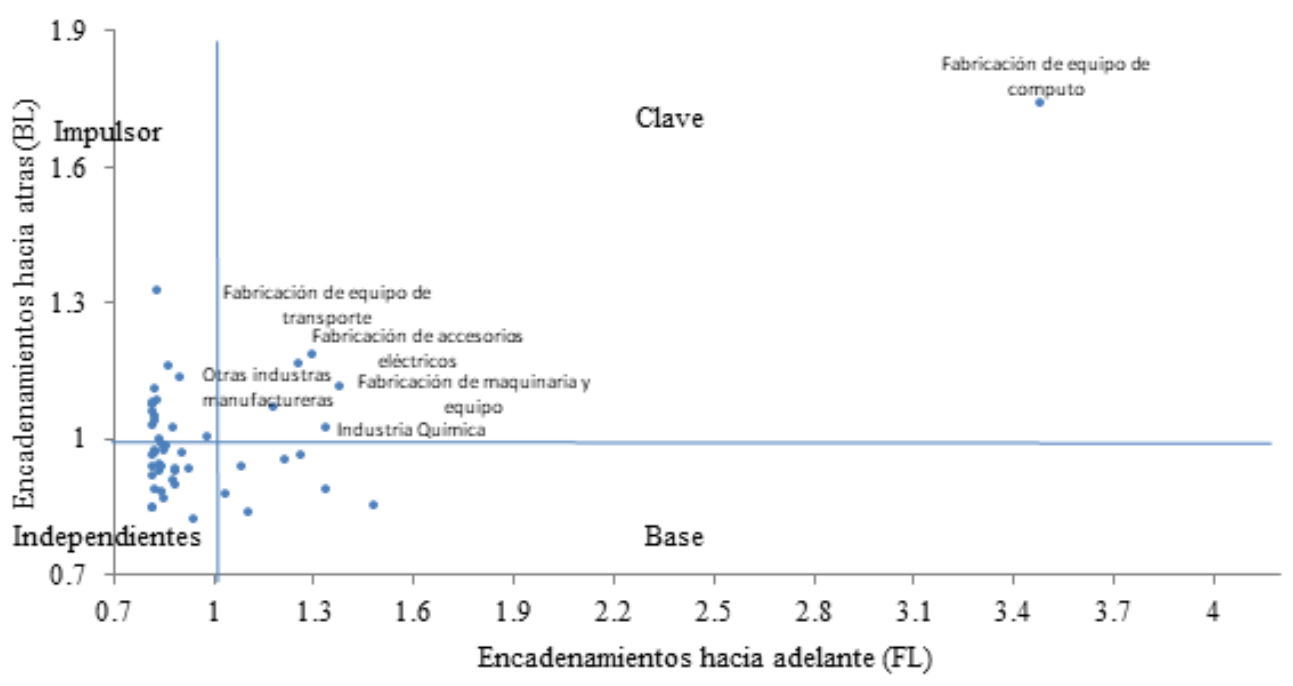

Fuente: Elaboración propia con base en la MIP Reynosa, 2013. 
Del modelo de Rasmussen es posible extraer dos posturas en relación con el perfil de la política industrial que se desee llevar a cabo en una región.

Una de ellas implica reconocer que la escasa diversificación sectorial se refleja en el rompimiento de numerosas cadenas productivas locales, lo que reduce la posibilidad de fortalecer el mercado interno (González y Barajas, 2004; Pérez, Ceballos y Cogco, 2014, pp. 201-202). Dicha alternativa, se eleva a favor de no discriminar industrias poco atractivas (sectores independientes) o cuyo desempeño no impacta significativamente a los sectores que demandan sus productos.

La otra postura se inclina por reconocer que la especialización en unas cuantas industrias conlleva a potenciar las ventajas competitivas regionales y, por consiguiente, a estimular las exportaciones (Porter, 2003). En este sentido, los partidarios de la especialización abogan por el impulso a subsectores con posibilidad de crecer y arrastrar ramas económicas que se encuentran en vías de convertirse en industrias clave. Se trata de una ideología que resalta la vocación regional a partir de considerar al sector manufacturero como eje central de crecimiento, lo cual implica un proceso excluyente tanto en el sentido de las actividades económicas como en el de la distribución territorial (Becerril, 2012).

En el caso de Reynosa es clara la influencia de la manufactura en las interdependencias productivas regionales, ejemplo de ello es el comportamiento de los subsectores clave dedicados a la fabricación de equipo de cómputo, maquinaria y equipo, aparatos eléctricos, equipo de transporte e industria química. Su particularidad es la fuerza que tienen como demandantes de insumos intersectoriales, pero también como oferentes de productos intermedios, además se ubican como un paso obligado de los diversos flujos sectoriales de la economía. Desde la óptica de especialización económica regional estas industrias tendrían que ser consideradas en el diseño de la política pública local, incluso por encima del riesgo que implica destinar recursos a sectores ampliamente dependientes del ciclo económico estadounidense.

Ahora bien, si lo que se busca es reducir la dependencia de la economía local en unos cuantos subsectores, habrán de considerarse aquellos clasificados en los cuadrantes base e impulsor; denominados así por la importancia de sus ventas y compras intersectoriales, respectivamente. En cuanto a los subsectores impulsores, sobresale la presencia de la economía terciaria, en particular de los servicios de almacenamiento, servicios de reparación y mantenimiento de vehículos automotores, así como telecomunicaciones. Por lo que respecta a los subsectores base se distingue la importancia de la fabricación de productos metálicos. Desde la perspectiva de la diversificación sectorial, estas actividades tendrían que formar parte de la agenda pública local ya que su condición al interior del sistema económico estimula la producción y el consumo de bienes intermedios, por lo que la dependencia a la industria manufacturera, maquiladora y de servicios de exportación tendería a reducirse. La estrategia de diversificación implicaría concentrar los esfuerzos institucionales en las empresas locales, a fin de reducir los riesgos del comercio exterior.

\section{Conclusiones}

Al examinar el desempeño histórico de la Tasa Media de Crecimiento Anual (20032013) referente al Producto Bruto Total de los municipios fronterizos más relevantes 
(Tijuana, Ciudad Juárez, Reynosa, Mexicali, Matamoros, Nuevo Laredo, Piedras Negras y Nogales), se confirmó que durante el periodo referido Reynosa representó uno de los territorios con mejor desempeño tanto en crecimiento como en participación en el PBT, equiparable con los valores registrados en las ciudades de Tijuana, Mexicali y Ciudad Juárez. Este bloque se ha posicionado en el contexto municipal fronterizo como el de mayor influencia económica, en términos del valor de su producción bruta total.

El desempeño regional analizado abre el permanente debate entre especialización (aglomerar firmas del mismo sector con el argumento de que el crecimiento se produce gracias al impulso de industrias con ventajas competitivas regionales) y diversificación económica (agrupar firmas de distintos sectores con el objeto de proveer servicios para las firmas y trabajadores con el argumento de que el crecimiento se genera mediante el desarrollo de la base industrial).

Si lo que se busca es fortalecer la posición del sector manufacturero como el eje central del crecimiento económico reynosense se tendría que considerar la influencia de la manufactura pesada en las interdependencias productivas regionales. Lo anterior se sustenta por la elevada concentración de empleo generado por la fabricación de equipos de cómputo, accesorios eléctricos y transporte (manufactura pesada). Se demostró que la capacidad manufacturera instalada en este territorio ejerce una fuerte demanda de insumos intersectoriales y oferta de productos intermedios, convirtiéndose en un paso obligado para el resto de los flujos económicos.

No obstante lo anterior, hay que ser cautelosos con la especialización de la industria manufacturera, maquiladora y de servicios de exportación; y es que la concentración industrial no ha promovido un mecanismo virtuoso que establezca una integración local a través del intercambio comercial. Lo anterior se refleja en: $I$ ) el valor marginal de los multiplicadores de producción, empleo, remuneración de los asalariados y valor agregado, para el resto de las actividades productivas; II) la débil magnitud de los encadenamientos productivos en las actividades de no manufactura y III) la escasa presencia del sector terciario (en términos de producción), en referencia a su contraparte nacional.

Al examinar las articulaciones del sistema y sus encadenamientos productivos a partir de una matriz de insumo-producto interregional se demostró que, la industria pesada no necesariamente implica que todos sus subsectores generen altos multiplicadores, ejemplo de ello fueron los resultados de la industria del plástico y del hule, y aquella vinculada a la fabricación de productos metálicos.

En cambio, si la intención es reducir la dependencia de la economía local en unos cuantos subsectores, se recomienda considerar la hegemonía de la manufactura ligera (fabricación de productos textiles y de prendas de vestir) y la economía terciaria (servicios de almacenamiento, compañías de fianzas y aquellas vinculadas con las telecomunicaciones). Los resultados mostraron que su condición al interior del sistema económico estimula la producción y el consumo de bienes intermedios. De forma que, al apoyar el desempeño de dichas actividades, se estaría fomentando el crecimiento de la economía reynosense, al cimentar las cadenas de proveeduría local.

Teniendo en cuenta lo anterior e independientemente del enfoque predilecto (especialización o diversificación) es recomendable el establecimiento de una política de crecimiento regional con visión de futuro que impulse las articulaciones del sistema. 
Por lo que respecta al método se precisa que la falta de información sobre producción interna bruta a nivel de municipio obstaculiza el análisis detallado del funcionamiento del entramado productivo, además, la ausencia de información actual (solo existe al año 2013) limita la precisión de los resultados estimados. No obstante, las derivaciones del modelo a partir de los aportes de Flegg et al. (1995; Flegg y Webber, 1997) y Rasmussen (1956) fueron idóneas para examinar el comportamiento de la estructura sectorial productiva de un municipio.

Si bien, la vocación productiva de Reynosa no es la agropecuaria, se recomienda incorporar información sobre dicho sector (compatible con el censo económico), esto permitiría mejorar las estimaciones del modelo de insumo-producto regional. Se trata, en todo caso, de construir una herramienta integral que observe a detalle la producción de bienes y servicios. En este escenario, la elaboración de una matriz municipal de contabilidad social o un modelo de equilibrio general, sería de gran utilidad como marco de referencia para el análisis estructural regional.

\section{Referencias}

Albornoz, L., Canto, R. y Becerril, J. (2012). La estructura de las interrelaciones productivas de la economía del estado de Yucatán. Un enfoque de insumo-producto. Región y Sociedad, 24(54). 133-174. Recuperado de http://www.scielo.org. $\mathrm{mx} / \mathrm{pdf} /$ regsoc/v24n54/v24n54a5.pdf

Aroche, F. (2013). La investigación sobre el modelo insumo-producto en México. Orígenes y tendencias. Estudios Económicos, 28(2), 249-264. Recuperado de http:// www.redalyc.org/pdf/597/59728813003.pdf

Becerril, I. (29 de noviembre de 2012). Pobre desempeño del sector industrial. $E l$ Financiero. Recuperado de http://biblioteca.iiec.unam.mx/index.php?option=com_content\&task=view\&id=18536\&Itemid $=146$

Berlingieri, G. (2014). Outsourcing and the Rise in Services (CEP Discussion Paper 1199). Recuperado de http://eprints.lse.ac.uk/51532/1/dp1199.pdf

Bonfiglio, A. (2005). Can Non-survey Methods Substitute for Survey-based Models? A Performance Analysis of Indirect Techniques of Estimating I-O Coefficients and Multipliers (Quaderno di Ricerca n. 230). Recuperado de http://docs.dises.univpm.it/ web/quaderni/pdf/230.pdf

Bonfiglio, A. y Chelli, F. (2008). Assessing the behaviour of non-survey methods for constructing regional input-output tables through a Monte Carlo simulation. Economic Systems Research, 20(3), 243-258. Recuperado de https://www.researchgate.net/publication/24078924_Assessing_the_Behaviour_of_Non-Survey_ Methods_for_Constructing_Regional_Input-Output_Tables_through_a_Monte_Carlo_Simulation

Bortkiewicz, L. von (1907). Value and Price in the Marxian System. Recuperado de http:// classiques.uqac.ca/classiques/Bortkiewicz_ladislaus_von/value_and_price_ marxian_system/value_price_marxian_system.pdf

Bravo, H. M. y Castro, J. (2006). Construcción de una matriz de contabilidad social con agua para el estado de Guanajuato (Documentos de trabajo número 176). Recuperado de http://www.libreriacide.com/librospdf/DTAP-176.pdf 
Cassel, G. (1924). Theory of Social Economy. Nueva York, Estados Unidos: Harcourt, Brace and Co.

Castro, G. (2010). Matriz insumo-producto y análisis estructural para el estado de Michoacán en el año 2003. Aplicación de un método de regionalización con corrección para el acarreo cruzado (Tesis de maestría). Recuperado de https://www.cise.uadec.mx/downloads/tesis/Maestria2008-2010_CRG.PDF

Chapa, J., Ayala, E. y Hernández, I. (2009). Modelo de insumo-producto para el noreste de México. Ciencia Universidad Autónoma de Nuevo León, XII(4), 409-416. Recuperado de https://dialnet.unirioja.es/descarga/articulo/3128859.pdf

Chenery, H. y Watanabe, T. (1958). International comparison of the structure of production. Econométrica, 26(4). Recuperado de https://www.jstor.org/stable/1907514

Chiquiar, D., Alvarado, J., Quiroga, M. y Torre, L. (2017). Regional Input-Output Matrices, an Application to Manufacturing Exports in Mexico (Working Papers, No. 201709). Recuperado de http://www.banxico.org.mx/publicaciones-y-prensa/documentos-de-investigacion-del-banco-de-mexico/\%7B12AAF90C-8036-6BBD-1A 4E-9DE123FE2280\%7D.pdf

Chraki, F. (2016). Análisis insumo-producto multirregional e integración económica del thcan. Una aplicación del método de extracción hipotética. Asociación de Cuadernos de Economía. Recuperado de http://www.elsevier.es/en-revista-cuadernos-economia-329-pdf-S021002661630053X

Dávila, A. (2002). Matriz de insumo-producto de la economía de Coahuila e identificación de sus flujos intersectoriales más importantes. Economía Mexicana Nueva Época, xI(1), 79-162. Recuperado de http://www.economiamexicana.cide.edu/ num_anteriores/XI-1/04_ALEJANDRO_DAVILA.pdf

Dávila, A. (2015). ¿Por qué y cómo elaborar modelos interregionales de insumo-producto mediante la aplicación de métodos indirectos de estimación? En A. Dávila (Coord.), Modelos interregionales de insumo-producto de la economía mexicana (pp. 7-26). Recuperado de https://www.cise.uadec.mx/downloads/LibrosElectronicos/LibroModelosInterregionales.pdf

Dávila, A. y Escamilla, A. (2013). Apertura comercial, cambios en la estructura productiva y desempeño de la economía de los estados de la frontera norte de México: 19932004. Región y Sociedad, xxv(56), 9-42. Recuperado de http://www.scielo.org.mx/ $\mathrm{pdf} / \mathrm{regsoc} / \mathrm{v} 25 \mathrm{n} 56 / \mathrm{v} 25 \mathrm{n} 56 \mathrm{a} 1 . \mathrm{pdf}$

Dietzenbacher, E., Linden, J. A. van dery Steenge, A. (1993). The regional extraction method: EC input-output comparisons. Economic System Research, 5(2), 185-206. Recuperado de https:/ / www.tandfonline.com/doi/abs/10.1080/09535319300000017

Esqueda, R. (2018). Disparidades en el desarrollo regional de Tamaulipas, México. Revista de Economía Institucional, 20 (38), 235-262. Recuperado de http://www. scielo.org.co/pdf/rei/v20n38/0124-5996-rei-20-38-00235.pdf

Esqueda, R. y Trejo, A. (2014). Desarrollo local, competitividad y apertura económica en Tamaulipas. Región y Sociedad, xxvI(59), 113-150. Recuperado de http://www.scielo. org.mx/pdf/regsoc/v26n59/v26n59a4.pdf

Flegg, A. T. y Tohmo, T. (2011). Regional input-output tables and the FLQ formula: A case study of Finland. Regional Studies, 47(5), 703-721. Recuperado de https:// hal.archives-ouvertes.fr/hal-00725360/document 
Flegg, A. T., Webber, C. D. y Elliot, M. V. (1995). On the appropriate use of location quotients in generating regional input-output tables. Regional Studies, 29(6), 547-561. Recuperado de https://www.tandfonline.com/doi/abs/10.1080/003 43409512331349173

Flegg, A. T. y Webber, C. D. (1997). On the appropriate use of location quotients in generating regional input-output tables: Reply. Regional Studies, 31(8), 795-805. Recuperado de https://www.tandfonline.com/doi/abs/10.1080/713693401

Fuentes, N. A. (2003). Encadenamientos insumo-producto en un municipio fronterizo de Baja California, México. Frontera Norte, 15(29), 151-184. Recuperadode http://www. scielo.org.mx/scielo.php?script=sci_arttext\&pid=S0187-73722003000100006

Fuentes, N. A. (2005). Construcción de una matriz regional de insumo-producto. Problemas del Desarrollo, 36(140), 89-112. Recuperado de http://www.redalyc. org/articulo.oa?id=11820092005

Fuentes, N., Brugués, A. y González, G. (2015). Modelo insumo-producto regional dinámico. Revista de Economía, XXXII(84), 79-107. Recuperado de http://www. revista.economia.uady.mx/2015/XXXII/84/3.pdf

Fuentes, N. A., Cárdenas, A. y Brugués, A. (2013). Análisis estructural de la economía de Baja California: Un enfoque de redes sociales. Región y Sociedad, xxv(57), 2760. Recuperado de http://www.scielo.org.mx/pdf/regsoc/v25n57/v25n57a2. pdf

Fuentes, N. A. y Castillo, G. del (2012). Reelaboración del modelo multisectorial dinámico para la planeación estratégica de la economía mexicana y simulación del Programa de Facilitación Comercial. Economía Mexicana Nueva Época, xxI(1), 5-33. Recuperado de http://www.scielo.org.mx/pdf/emne/v21n1/v21n1a1. pdf

García, A. y Ramos, C. (2003). Las redes sociales como herramienta de análisis estructural input-output. Revista Hispana para el Análisis de Redes Sociales, 4(5), 1-21. Recuperado de http://revista-redes.rediris.es/html-vol4/vol4_5.htm

Ghosh, A. (1958). input-output approach to an allocation system. Economica, (25), $58-64$.

González, G. y Barajas, M. (2004). Los procesos de aprendizaje en la industria maquiladora. ¿Una senda predefinida? En J. Carrillo y R. Partida (Coords.), La industria maquiladora mexicana: Aprendizajes tecnológicos, impactos regionales y entornos institucionales (pp. 4-7). Recuperado de https://www.researchgate.net/ profile/Jorge_Carrillo7/publication/268406984_La_Industria_Maquiladora_ Mexicana_Aprendizajes_tecnologicos_impactos_regionales_y_entornos_institucionales/links/55db8eb708aec156b9afedd8/La-Industria-Maquiladora-Mexicana-Aprendizajes-tecnologicos-impactos-regionales-y-entornos-institucionales. pdf

González, R., Díaz, M. y Leal, F. (2010). Identificación de sectores estratégicos en la economía de Aguascalientes. Investigación y Ciencia, 18(49), 40-47. Recuperado de http://www.redalyc.org/pdf/674/67415178007.pdf

Hurtado, A. y Martínez, E. (2017). Redes binarias y la matriz insumo-producto: Una aplicación regional. Trayectorias, 19(45), 57-76. Recuperado de http://trayectorias.uanl. $\mathrm{mx} / 45 / \mathrm{pdf} / 3 . \mathrm{pdf}$ 
Instituto Nacional de Estadística y Geografía (Inegi). (2004). Censo Económico 2004. Sistema Automatizado de Información Censal (SAIC). Recuperado de http://www. beta.inegi.org.mx/app/saic/

Instituto Nacional de Estadística y Geografía (Inegi). (2009). Censo Económico 2009. Sistema Automatizado de Información Censal (SAIC). Recuperado de http://www. beta.inegi.org.mx/app/saic/

Instituto Nacional de Estadística y Geografía (Inegi). (2014). Censo Económico 2014. Sistema Automatizado de Información Censal (SAIC). Recuperado de http://www. beta.inegi.org.mx/app/saic/

Instituto Nacional de Estadística y Geografía (Inegi). (2018). PIB y Cuentas Nacionales. Matriz de Insumo Producto. Base 2013. Recuperado de http://www.beta.inegi.org. $\mathrm{mx} / \mathrm{temas} / \mathrm{mip} /$

Johnson, T. (1986). A dynamic input-output model for small regions. Review of Regional Studies, 16(1), 14-23. Recuperado de http://journal.srsa.org/ojs/index.php/ RRS/article/view/16.1.3/758

Kronenberg, T. (2011). Regional input-output models and the treatment of imports in the European system of accounts (ESA). Review of Regional Research, 32(2), 175191. Recuperado de https://www.researchgate.net/publication/271923370_ Regional_input-output_models_and_the_treatment_of_imports_in_the_European_System_of_Accounts_ESA

Leontief, W. (1936). Quantitative input-output relations in the economic system of the United States. Review of Economics and Statistics, 18(3), 105-125.

Leontief, W. (1941). The Structure of American Economy 1919-1939. Nueva York, Estados Unidos: Oxford University Press.

Llano, C. (2009). Efectos de desbordamiento interregional en España: Una estimación a través del modelo input-output interregional. Investigaciones Regionales, (16), 181-188. Recuperado de https://repositorio.uam.es/bitstream/ handle/10486/668295/DesbordamientoInterregional_Llano_IR_2009.pdf?sequence $=1 \&$ isAllowed $=\mathrm{y}$

Martínez, E. y Gómez, R. (2008). Complejidad de las relaciones sectoriales en la educación. Inceptum, (4), 83-97. Recuperado de https://www.inceptum.umich.mx/ index.php/inceptum/article/download/42/34

Miller, R. y Blair, P. (2009). Input-Output Analysis: Foundations and Extensions. Recuperado de http://static.gest.unipd.it/ birolo/didattica11/Materiale_2012/_ Materiale_2015/Miller_Blait-input-output_analysis.pdf

Molina, A. H. y Gutiérrez, R. R. (2015). Reformulación del modelo de Leontief a través de redes de Petri. Ciencia y Tecnología, (15), 83-96. Recuperado de https://www. palermo.edu/ingenieria/pdf2015/15/CyT_15_06.pdf

Organización de las Naciones Unidas (ONU). (2018). Handbook on Supply, Use and Input-Output Tables with Extensions and Applications. Recuperado de https://unstats. un.org/unsd/nationalaccount/docs/SUT_IOT_HB_wc.pdf

Pareto, V. (1906). Manual of Political Economy. Nueva York, Estados Unidos: A. M. Kelley.

Pérez, J., Ceballos, G. y Cogco, A. (2012). Los planteamientos del desarrollo local y su relación con la industria y los encadenamientos productivos: un análisis de la dinámica manufacturera en la estructura sectorial en las principales ciudades del estado de Tamaulipas, 2004. En A. R. Cogco, M. Rodríguez y J. Pérez 
(Coords.), Acciones y reflexiones para la reconstrucción de la política social en México. Una mirada desde lo local (pp. 83-106). Recuperado de http://riuat.uat.edu.mx/ bitstream/123456789/1505/1/1505.pdf

Pérez, J., Ceballos, G. y Cogco, A. (2014). Los factores que explican la mayor aglomeración de la industria de alta tecnología en la frontera norte de México: El caso de Matamoros y Reynosa. Estudios Fronterizos 15(29), 173-206. Recuperado de http://ref.uabc.mx/ojs/index.php/ref/article/view/51/66?lan=es_ES

Porter, M. (2003). The economic performance of regions. Regional Studies, 37(6\&7), 549-578. Recuperado de https://pdfs.semanticscholar.org/de0e/a94b8048b7e7ce4d1ac7193d9bfb9847f735.pdf

Quesnay, F. (1759). Le Tableau Économique (Editado y traducido al inglés por M. Kuczynski y R. L. Meek). Londres, Reino Unido: Macmillan.

Rasmussen, P. (1956). Studies in Inter-Sectorial Relations. Copenhague, Dinamarca: Einar Harks.

Salinas, E., González, M., León, A. y Rodríguez, F. (2017). La actividad forestal en el desarrollo económico de Chignahuapan, Puebla. Región y Sociedad, xxIX(69). Recuperado de http://www.redalyc.org/pdf/102/10250503007.pdf

Schuschny, A. R. (2005). Tópicos sobre el modelo de insumo-producto: Teoría y aplicaciones (Serie estudios estadísticos y prospectivos, 37). Recuperado de https://repositorio.cepal.org/bitstream/handle/11362/4737/S0501011_es.pdf?sequence=1

Tapia, G., Vite, M., Salazar, I. y Zamora, R. (2010). Riesgos de un incremento del gasto en educación en el valor bruto de la producción del municipio de Huetamo. Un análisis de insumo-producto. Ecorfan, 1(1), 31-50. Recuperado de https:// dialnet.unirioja.es/descarga/articulo/4029493.pdf

Valdés, M. (2014). Apertura comercial y desempeño de la economía del estado de Jalisco. Un análisis multisectorial de insumo-producto (Tesis doctoral). Recuperado de https:/ / www.cise.uadec.mx/downloads/tesis/Doctorado2010-2013_VIM.PDF

Walras, L. (1874). Elements of Pure Economics. París, Francia: Guillaumin \& Cie. 
Rodrigo Vera Vázquez

Mexicano. Rector de El Colegio de Tamaulipas. Tiene doctorado en Ciencias Sociales por El Colegio de Michoacán y maestría en Administración Integral del Ambiente por El Colegio de la Frontera Norte, ambos programas registrados en el PNPC del Conacyt en la modalidad de competencia internacional. Líneas de investigación: geografía económica transfronteriza y desarrollo regional. Es evaluador de proyectos de investigación del Conacyt y de programas sociales del sector público. Entre sus publicaciones más recientes: Eagle Ford Shale Play: Geografía Industrial MineroPetrolera en el Sur de Texas, 2008-2015. Trayectorias, 19(45), 3-36.

Miguel Angel Langle Flores

Mexicano. Ingeniero Químico por la Universidad de Guanajuato, maestro en Economía (PNPC) por la misma institución y doctorado en Economía Regional (PNPC) por la Universidad Autónoma de Coahuila. Actualmente se desempeña como profesorinvestigador en El Colegio de Tamaulipas y forma parte de la Red de Investigación en Economía Regional y Urbana. Líneas de investigación: temas de economía regional y modelos regionales multisectoriales. Entre sus publicaciones más recientes: Langle M., Dávila A. y Valdés M. (2019). Desarticulación productiva de la región sur de México. En A. Dávila (Coord.), Modelos económicos de las regiones de México. México: Universidad Autónoma de Coahuila y Miguel Ángel Porrúa. 